\title{
Sleep Apnea and the Kidney
}

\section{Oreste Marrone $^{1} \cdot$ Maria Rosaria Bonsignore ${ }^{1,2}$}

Published online: 27 July 2020

(C) The Author(s) 2020

\begin{abstract}
Purpose of Review There are some uncertainties about the interactions between obstructive sleep apnea (OSA) and chronic kidney disease (CKD). We critically reviewed recent studies on this topic with a focus on experimental and clinical evidence of bidirectional influences between OSA and CKD, as well as the effects of treatment of either disease.

Recent Findings Experimental intermittent hypoxia endangers the kidneys, possibly through activation of inflammatory pathways and increased blood pressure. In humans, severe OSA can independently decrease kidney function. Treatment of OSA by CPAP tends to blunt kidney function decline over time, although its effect may vary. OSA may increase cardiovascular complications and mortality in patients with end-stage renal disease (ESRD), while it seems of little harm after renal transplantation. Excessive fluid removal may explain some of the improvements in OSA severity in ESRD and after transplantation. Summary Severe OSA and CKD do interact negatively, mainly through hypoxia and fluid retention. The moderate mutually interactive benefits that treatment of each disease exerts on the other one warrant further studies to improve patient management.
\end{abstract}

Keywords Sleep-disordered breathing $\cdot$ Renal function $\cdot$ Hemodialysis $\cdot$ Kidney transplantation $\cdot$ CPAP

\section{Introduction}

Both obstructive sleep apnea (OSA) and chronic kidney disease (CKD) are common in the general population [1,2]. An interrelationship between the two diseases is increasingly recognized, but interdisciplinary approaches to their treatment are highly variable, since both are usually managed by different medical specialists. Despite the fact that the evidence gathered from clinical and epidemiological observations conducted so far still leave some room to uncertainty about independent interrelations between OSA and CKD, there is a large body of biological data that support the plausibility of these interactions.

This article is part of the Topical Collection on Sleep and Sleep Apnea at the Extremes

Maria Rosaria Bonsignore

marisa.bonsignore@irib.cnr.it

1 Istituto per la Ricerca e l'Innovazione Biomedica, National Research Council (CNR) of Italy, Palermo, Italy

2 Respiratory Sleep Clinic, Dipartimento di Promozione Della Salute, Materno-Infantile, Medicina Interna e Specialistica di Eccellenza "G. D'Alessandro" (PROMISE), University of Palermo, Piazza delle Cliniche, 2, 90127 Palermo, Italy
On the one hand, OSA is associated with intermittent hypoxemia, increased blood pressure and sympathetic activity, obesity, and metabolic alterations [3], all of which may endanger renal integrity and lead to increased albumin excretion and accelerated decline in glomerular filtration rate (GFR) over time. These mechanisms could lead to an increased incidence of CKD and to a more rapid trajectory towards endstage renal disease (ESRD) in OSA patients. On the other hand, uremia and metabolic acidosis associated with renal dysfunction may increase chemoreceptor reactivity and destabilize breathing patterns, predisposing patients to both obstructive and central apnea. Besides, fluid retention due to inefficient glomerular filtration may be followed by rostral fluid shift when assuming a recumbent posture, leading to decreased cross-sectional pharyngeal area and obstructive apneas, or, particularly in patients with cardiac disease, to interstitial lung edema, hyperventilation, and central apneas [4].

Nowadays, the attention of physicians managing patients with OSA is mainly directed to symptoms and possible cardiovascular complications, and to a much lesser extent to the possible kidney involvement. Actually, the importance of addressing renal effects of OSA is not entirely clear. Renal consequences of OSA are less known than cardiovascular complications. Besides, direct evidence of the independent detrimental effects of untreated OSA, and of benefits of OSA 
treatment, on the kidneys is less strong compared to data obtained in animal experiments. As nephrologists are concerned, screening and treatment of OSA in CKD and ESRD have not entered general clinical practice yet.

In this review, we summarize recent data obtained in animal models on the pathogenesis of CKD in OSA, highlight the current evidence that may support a direct influence of OSA on kidney function, and try to account for the uncertainties and contradictory interpretations found in the current literature. In addition, we will examine the clinical implications of sleepdisordered breathing (SDB) in patients with renal disease, paying particular attention to those with ESRD or receiving transplantation. We will illustrate the present knowledge on the effects of dialysis and transplantation on SDB, as well as of OSA treatment on kidney function, which are topics still requiring extensive investigation.

\section{Evidence of Renal Damage in Experimental Models of OSA}

OSA typically causes intermittent hypoxia (IH) during sleep. Several studies in mouse and rat models assessed the impact of $\mathrm{IH}$ on the kidney. A major advantage of animal models is the possibility to study the effects of $\mathrm{IH}$ without the confounding variables occurring in human OSA, but the IH models do not provide data on the effects of intermittent hypercapnia associated with IH in OSA. One study assessed the effects of IH and $\mathrm{IH}$ associated with hypercapnia and suggested a possible protective effect of $\mathrm{CO}_{2}$ on inflammatory markers, but duration of exposure was short, warranting further study [5॰].

Acute exposures to IH caused minimal or no pathological changes and increased renal blood flow and GFR [6]. Conversely, chronic IH was associated with evidence of glomerular and tubular damage [6, 7]. The pathological findings included an increase in glomerular area, expansion of mesangial matrix, and increased apoptosis $[7,8]$. As for functional changes, increased albuminuria [7] and reduced renal flow, GFR, and sodium transport were found after chronic IH exposures [6].

The molecular mechanisms involved in IH-induced renal injury are complex, with involvement of several pathways, such as the receptor for advanced glycation end-product (RAGE) [9] and its ligand, the high-mobility group box 1 protein (HMGB1) [5, 9], toll-like receptor 4 (TLR-4) [10], oxidative stress [11•] and the NLRP3 inflammasome [12]. Blockade of such pathways resulted in decreased tubular damage, collagen deposition and apoptosis, lower release of inflammatory cytokines, and blunted albuminuria $[9,10,11 \bullet, 12]$.

Chronic IH exposure causes hypertension in rodents $[8$, 13]. The studies on kidney function did not always monitor blood pressure during chronic $\mathrm{IH}$, raising the question about the confounding contribution of hypertension to kidney damage. In a complex experimental model of alanineinduced CKD followed by exposure to chronic $\mathrm{IH}$, blocking endothelin (ET)-a and ET-b receptors prevented hypertension but not tissue injury [14••]. Conversely, Angiotensin 1-7, which counters the effect of Angiotensin-2, was found to blunt the effects of chronic IH on renal sympathetic activity, inflammation, and fibrosis [8]. Moreover, recent studies in which telmisartan and losartan were administered during chronic IH exposure suggested protective effects of these drugs on kidney injury $[15,16]$. More studies are clearly needed to understand to what extent IH-induced kidney damage may be at least partly mediated by hypertension.

\section{Epidemiology of the Association Between OSA and CKD}

Despite unquestionable evidence of risk factors for CKD in OSA, the presence of confounders makes an independent link between the two conditions difficult to demonstrate in human patients. These confounders include advanced age, obesity, and especially comorbidities like arterial hypertension and diabetes mellitus. Therefore, one important requirement for epidemiological studies on OSA and CKD is a large sample of subjects in order to adjust for multiple confounders. In addition, ideally, the sample sizes of subjects with CKD, OSA (from mild to severe), and healthy controls should be adequately balanced, which is difficult to obtain. In fact, studies performed in general population samples, while showing little or no selection bias in subjects' recruitment, predominantly included healthy subjects, and the few OSA patients in the sample had a mild disease with little nocturnal hypoxemia. Conversely, studies on patients with suspected OSA included subjects with worse risk factors for CKD and more severe hypoxemia, with higher probability to show significant effects of OSA on renal function, but low applicability of results to the general population.

In the last several years, large epidemiological studies have been published. Among recent cross-sectional studies on the general population, a significant increase in the prevalence of $\mathrm{SDB}$, considered as apnea/hypopnea index (AHI) $\geq 15 / \mathrm{h}$ of total sleep time (hrTST), was observed from non-CKD to CKD stages 1-2 to CKD stage 3 subjects in the HypnoLaus cohort in Swtizerland; however, CKD stage and estimated GFR (eGFR) quartile did not independently predict SDB [17]. The other available cross-sectional study observed a significant effect of AHI on CKD prevalence but, unsurprisingly, no effect of nocturnal hypoxemia: in fact, hypoxia among the recruited subjects was very mild [18•]. The longitudinal study on the general population in the Wisconsin cohort found that both the decline in eGFR and CKD incidence were similar in subjects with and without sleep apnea. However, patients with 
sleep apnea, defined as AHI $\geq 15 / \mathrm{hrTST}$, were few (90/855 subjects) and oxygen saturation values were not reported [19].

Among investigations on subjects with suspected sleep apnea, one longitudinal study demonstrated that an increased rate of decline in eGFR occurred when $\geq 12 \%$ of sleep time was spent with oxygen saturation $\left(\mathrm{SaO}_{2}\right)<90 \%$ [20••], a threshold uncommon in significant proportions of subjects of general population samples. Accordingly, a multicenter cross-sectional study on a sleep laboratory population found that lowest nocturnal $\mathrm{SaO}_{2}$ independently predicted eGFR $<$ $60 \mathrm{ml} / \mathrm{min} / \mathrm{m}^{2}$ [21•]. Both these studies did not find any independent effect of $\mathrm{AHI}$ as a risk factor for CKD.

Finally, some recent longitudinal studies analyzed data taken from registries, with the advantage of including very large number of patients with diagnosed sleep apnea and controls. Common pitfalls of these studies are that no polysomnographic data were available, and information on continuous positive airway pressure (CPAP) prescription, when available, was not associated with data on actual CPAP use. Nevertheless, these studies agreed that OSA is likely to be a risk factor for the kidneys since it was associated with faster annual decline in eGRF [22•] and higher incidence of CKD [23-25] and of ESRD [26•].

Altogether, most epidemiological studies support an independent association between OSA and CKD. This association primarily involves patients with severe OSA, while it is much more uncertain for mild cases of sleep apnea. So far, attention has been paid mainly to the possible importance, as risk markers, of classic polysomnographic variables, i.e., AHI and hypoxemia parameters. Future studies may explore roles of other factors that are often altered in OSA, like 24-h blood pressure profile or insulin sensitivity.

\section{Sleep Apnea and ESRD}

Sleep apnea is common in patients with CKD, and its prevalence progressively increases with CKD severity [27]. Patients with ESRD show the highest prevalence, possibly because in ESRD, some risk factors for SDB, such as fluid retention and high chemoresponsiveness, are more common and severe than in milder CKD. ESRD patients with OSA have higher BMI and neck circumference than those without OSA [28-30], but they are thinner compared to typical OSA patients seen in sleep laboratories, and more rarely report typical OSA symptoms, like heavy snoring or excessive daytime sleepiness [31-33]. ESRD patients report poor sleep quality, but periodic leg movements [34] rather than SDB $[35,36]$ likely play a role.

However, several observations suggest that sleep apnea may be detrimental also in patients with ESRD (Table 1). One effect of occurrence of SDB in ESRD may be an overnight decrease in systolic and diastolic myocardial function [37••], as already observed in patients with heart failure [38].
Improvement of SDB, obtained with reduction in body fluids by plasma ultrafiltration, may blunt such deterioration [37••]. Recent studies have shown that, in the long term, OSA may increase cardiovascular and all-cause mortality in middle-aged ESRD patients $[39,40]$. This effect was not demonstrated in older patients who, rather the opposite, showed a lower risk of all-cause death, myocardial infarction, and ischemic stroke when they had been diagnosed with OSA [41]. This is in agreement with observations in other populations reporting a lower coronary and mortality risk, if not an advantage, in elderly OSA patients $[42,43]$. Mortality risk in middle-aged ESRD patients was related to nocturnal hypoxemia, and not to AHI [40], as already found in a previous small study [44].

\section{Fluid Overload, Dialysis, and Sleep-Disordered Breathing}

Rostral shift of fluids when assuming the recumbent posture has been identified as an important determinant of apnea in patients with ESRD. In these patients, overnight change in leg fluid volume correlated with apnea/hypopnea time in acute studies [45]. Over an average 8-month time period, it was observed that remission of nephrotic syndrome was associated with a reduction in AHI that was attributed to remission of limb edema [46]. Two more recent studies found that patients with a high AHI had a higher extracellular fluid volume in nondialysis days [47] and a higher interdialytic weight gain [48].

Patients undergoing hemodialysis acutely reduce fluid retention and, at the same time, remove uremic toxins thus improving their metabolic status. Interestingly, if in a nondialysis day ESRD patients are submitted to plasma ultrafiltration, leading to fluid removal without alterations in acid base balance or plasma metabolic components, their AHI decreases proportionally to the reduction in extracellular fluid volume [49॰]. Such data strongly support a major role of fluid removal as responsible for the beneficial effect of dialysis on SDB. However, only minor, non-significant changes in AHI have been reported between nights preceding and following dialysis $[28,32,50 \bullet]$. One recent study showed that changes in obstructive AHI after dialysis were correlated to changes in fluid overload but confirmed that the average difference in AHI between nights before and after dialysis was not significant [51].

Different results have been reported with a stable change in dialysis regimen. After transition from conventional (threediurnal sessions per week) to nocturnal (six nights per week) [50••], as well as from continuous ambulatory peritoneal dialysis to nocturnal dialysis [52], AHI significantly improved, with decrease in both central and obstructive apneas. Nocturnal dialysis, besides better reverting physiological perturbations of uremia [53], more effectively decreases sympathetic activity than conventional dialysis [54]. The lower 
Table 1 Recent studies on effects of sleep apnea in patients with end stage renal disease (ESRD)

\begin{tabular}{|c|c|c|c|c|c|}
\hline Authors & No. of subjects recruited & $\begin{array}{l}\text { Sleep apnea } \\
\text { diagnosis }\end{array}$ & No. of subjects with OSA & Follow-up duration & Outcomes \\
\hline Tuohy et al. [41] & $\begin{array}{r}184,217 \text { patients } \geq 67 \text { years } \\
\text { old starting hemodialysis }\end{array}$ & $\begin{array}{l}\text { Diagnosis based on } \\
\text { ICD- } 9 \text { criteria in } \\
\text { the } 2 \text { years } \\
\text { before starting } \\
\text { hemodialysis }\end{array}$ & $15,121 \mathrm{SDB}$ & Mean 1.6 years & $\begin{array}{l}\text { SDB associated with lower } \\
\text { risk of all-cause death, } \\
\text { myocardial infarction and } \\
\text { ischemic stroke; no effect } \\
\text { on atrial fibrillation }\end{array}$ \\
\hline Kerns et al. [39] & $\begin{array}{l}558 \text { incident hemodialysis } \\
\text { patients, mean age } 56\end{array}$ & $\begin{array}{l}\text { Chart reviews of } \\
\text { clinical medical } \\
\text { records available } \\
\text { in the year prior } \\
\text { to dialysis } \\
\text { initiation }\end{array}$ & 66 OSA & Mean 23.2 months & $\begin{array}{l}\text { OSA associated with all-cause } \\
\text { and cardiovascular } \\
\text { mortality and with sudden } \\
\text { cardiac death }\end{array}$ \\
\hline Inami et al. $[37 \bullet \bullet]$ & 15 ESRD patients & Polysomnography & $\begin{array}{l}6 \text { OSA } \\
2 \text { CSA }\end{array}$ & $\begin{array}{l}1 \text { day (evening to } \\
\text { morning, and night } \\
\text { pre-post plasma } \\
\text { ultrafiltration) }\end{array}$ & $\begin{array}{l}\text { Sleep apnea associated with } \\
\text { overnight decrease in } \\
\text { systolic and diastolic } \\
\text { function in ESRD; } \\
\text { improved SDB after body } \\
\text { fluid removal }\end{array}$ \\
\hline Jhamb et al. [40] & $\begin{array}{l}\text { Stage } 4-5 \text { CKD }(n=88) \\
\text { and } \operatorname{ESRD}(n=92), \\
\text { mean age } 54\end{array}$ & Polysomnography & $\begin{array}{l}45 \text { mild } \\
42 \text { moderate } \\
41 \text { severe } \\
\text { predominantly obstructive } \\
\quad \text { sleep apnea }\end{array}$ & Median 9 years & $\begin{array}{l}\text { Relationships of mortality } \\
\text { with nocturnal hypoxemia, } \\
\text { but not with AHI }\end{array}$ \\
\hline
\end{tabular}

sympathetic activity could be associated with a greater decrease in chemoresponsiveness, which, in turn, could contribute to the improvement in SDB [55].

Children on dialysis show poor sleep quality [56-58] and prevalence of sleep-disordered breathing is estimated around $40 \%[56,59]$. One study reported higher AHI in patients compared to controls [58], but another study in children on automatic peritoneal dialysis found mild SDB in children with ESRD [57]. In summary, positive effects of dialysis on SDB in adult patients with ESRD are likely, but their mechanisms and the effects of pediatric ESRD are still incompletely understood.

\section{Kidney Transplant and Sleep Apnea}

After kidney transplantation, reversal of uremia and fluid overload could be expected to improve pre-existing sleep apnea. However, inconsistent results have been reported about the effects of transplantation on sleep apnea [60, 61]. Most of the studies were on small case series and did not adequately take into account factors such as OSA severity before transplantation, reduction in fluid overload, or change in body weight after transplantation. One recent, relatively large, controlled study on patients with a pretransplant $\mathrm{AHI} \geq 15 / \mathrm{hrTST}$ demonstrated that after transplantation, AHI decreased proportionally to the decrease in fluid overload, although an increase in body fat tended to blunt the change in AHI [62••].
Evidence of unfavorable effects of sleep apnea in transplanted patients is scant (Table 2). It relies mainly on a paper showing that subjects transplanted after 2008 who were diagnosed with sleep apnea had a higher risk of graft loss, although their risk of death with functioning graft was not increased [63]. Three other studies, while confirming the lack of any influence of OSA [64, 65•], or risk of OSA [66], on mortality in transplanted patients, did not find any effect of OSA on rate of decline in eGFR [64] or in return to dialysis or retransplantation [65*]. Harmlessness of sleep apnea after transplantation has been hypothesized to be a consequence of the denervation of the transplanted kidneys, which may blunt apnea-induced sympathetic overactivation $[64,65 \cdot]$. According to another theory, ischemic preconditioning due to recurrent apneas could determine long-term benefits in transplanted patients [65॰], as already hypothesized for ischemic cardiac disease [42].

In transplanted children, $61 \%$ of the sample showed evidence of OSA that was moderate-severe in $38.5 \%$ and associated with uncontrolled hypertension. However, SDB was likely to be overestimated, since prevalence of obesity and metabolic abnormalities tended to be higher in children undergoing PSG compared to children refusing participation to the study [67].

\section{Effects of CPAP Therapy on Kidney Function}

CPAP is the therapy of OSA that more fully prevents occurrence of SDB. Its main limitation is related to variable adherence to its use, which leaves some patients incompletely 
Table 2 Effects of sleep apnea in patients receiving kidney transplant

\begin{tabular}{|c|c|c|c|c|c|}
\hline Authors & $\begin{array}{l}\text { No. of subjects } \\
\text { recruited }\end{array}$ & $\begin{array}{l}\text { Sleep apnea diagnosis/ } \\
\text { risk }\end{array}$ & $\begin{array}{l}\text { No. of subjects with } \\
\text { sleep apnea }\end{array}$ & Follow-up duration & Outcomes \\
\hline Szentkiralyi et al. [66] & 823 adults & $\begin{array}{l}\text { Berlin questionnaire } \\
\text { after transplant }\end{array}$ & 226 & Median 66 months & $\begin{array}{l}\text { OSA risk was associated with graft loss } \\
\text { in females, but did not influence } \\
\text { all-cause mortality }\end{array}$ \\
\hline Fornadi et al. [64] & 100 adults & $\begin{array}{l}\text { Polysomnography after } \\
\text { transplant }\end{array}$ & $\begin{array}{l}18 \text { mild } \\
11 \text { moderate } \\
14 \text { severe }\end{array}$ & Median 75 months & $\begin{array}{l}\text { No effect of AHI or of OSA diagnosis on } \\
\text { rate of decline of eGFR or on } \\
\text { all-cause mortality and time to death }\end{array}$ \\
\hline Lubas et al. [63] & 322 adults & $\begin{array}{l}\text { Medical records } \\
\text { documenting sleep } \\
\text { apnea before } \\
\text { transplant of after } \\
\text { transplant before } \\
\text { graft loss }\end{array}$ & 60 & Up to 20 years & $\begin{array}{l}\text { Sleep apnea did not influence mortality } \\
\text { with functioning graft but was } \\
\text { associated with higher risk of graft } \\
\text { loss in patients transplanted after } 2008\end{array}$ \\
\hline Tiwari et al. [65•] & 4014 adults & $\begin{array}{l}\text { Medical records } \\
\text { documenting sleep } \\
\text { apnea }\end{array}$ & $\begin{array}{l}415 \text { diagnosed before } \\
\text { transplant } \\
117 \text { diagnosed } \\
\text { after transplant }\end{array}$ & Median 6.1 years & $\begin{array}{l}\text { No influence of sleep apnea on acute } \\
\text { kidney rejection, return to dialysis, } \\
\text { re-transplantation or mortality }\end{array}$ \\
\hline
\end{tabular}

treated. Its favorable effects on patients' symptomatology are undiscussed, whereas benefits on other health aspects, like cardiovascular and metabolic manifestations, are small and still controversial [68].

CPAP therapy is associated with a reduction in common risk factors for $\mathrm{CKD}$, which could warrant an improvement in kidney function. CPAP prevents nocturnal oxygen desaturations, slightly decreases blood pressure [69], and reduces renal RAS activity [70] and circulating inflammatory markers including IL-18, a marker of acute kidney injury [71].

All uncontrolled studies support a benefit of CPAP on both albumin excretion and GFR. The decrease in albumin

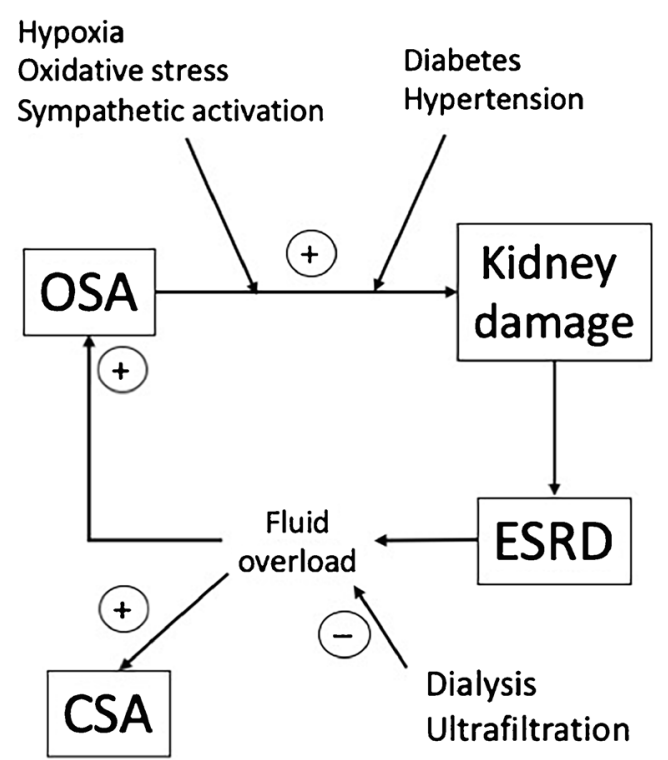

Fig. 1 Summary of the mechanisms by which OSA can worsen chronic kidney disease (CKD) and end-stage renal disease (ESRD) can cause sleep-disordered breathing. OSA: obstructive sleep apnea. CSA: central sleep apnea excretion was evident in morning, but not in evening, urine samples, suggesting that SDB exerts acute detrimental effects that may be prevented by treatment [72]. Good compliance to CPAP therapy is necessary for a reduction in albuminuria to occur $[73,74]$. Small studies addressing GFR consistently found benefits of CPAP therapy, as shown by decreased glomerular hyperfiltration [70, 75], blunted decline in eGFR [76], or even increase in eGFR [77]. One large multicenter cohort study compared changes in eGFR over time in patients who were untreated or treated by auto-CPAP or by fixed CPAP. While in the first two groups, a larger eGFR decline was observed in the patients who had a longer follow-up, eGFR remained substantially unchanged irrespective of follow-up duration in those treated by fixed CPAP. The changes in eGFR after fixed, but not after auto-CPAP, significantly differed from the changes after no OSA treatment [78•]. In contrast, the only RCT published so far on the effects of CPAP reported that mean changes in eGFR over time were small and did not significantly differ between patients under usual care or CPAP treatment [79॰]. However, even in this study, a nonsignificant trend to a better evolution of eGFR with CPAP was observed.

A large interindividual difference in changes in eGFR after CPAP, which emerged in different studies [78•, 79•], may make it difficult to clearly demonstrate independent effects of CPAP. Age of the patients, baseline CKD function and OSA severity, duration of follow-up, comorbidities, drug therapies, and type of CPAP treatment are some of the factors that can influence the variability in eGFR time course. Discordant results and highly variable interindividual differences have been also reported for blood pressure changes after CPAP, and only meta-analyses on a high number of studies have been able to consistently demonstrate that CPAP decreases blood pressure, although by a small extent [69]. Similarly, we 
believe that a high number of studies with many patients would be necessary to definitely demonstrate benefits of CPAP treatment on kidney function.

\section{Conclusions}

Experimental studies underpin the existence of biologically relevant interactions between OSA and CKD. In animals, the role of intermittent hypoxia as a factor endangering kidney function is evident, although it is still unclear to what extent the changes observed in kidney structure and function may be at least partly mediated by underlying increased blood pressure. The results of human studies are summarized in Fig. 1. Epidemiological studies have confirmed the detrimental effect of OSA on kidney function and on prognosis of patients with ESRD, which is more evident when OSA is severe. On the other hand, excessive fluid retention causes or worsens OSA in CKD, especially in ESRD. Many still poorly known factors, in addition to hypoxia and fluid overload, may come into play in the interaction between OSA and CKD, enhancing, or blunting, their effects. Among these factors, blood pressure levels and 24-h profile could have a prominent role, which deserves further careful studies. Effects of treatment of OSA or CKD on the other disease seem on average rather weak. Some confounders and interacting factors that could reduce the benefits of treatment are known, but the effects of OSA therapy remain incompletely understood and poorly predictable. Studies aimed at better understanding the complex effects that dialysis and kidney transplantation may exert on respiratory function during sleep, as well as of the mechanisms through which CPAP influences renal function, would be extremely useful to improve patients' management.

Funding Information Open access funding provided by Università degli Studi di Palermo within the CRUI-CARE Agreement.

\section{Compliance with Ethical Standards}

Conflict of Interest The authors declare that they have no conflicts of interest relevant to the article.

Human and Animal Rights This article does not contain any studies with human or animal subjects performed by any of the authors.

Open Access This article is licensed under a Creative Commons Attribution 4.0 International License, which permits use, sharing, adaptation, distribution and reproduction in any medium or format, as long as you give appropriate credit to the original author(s) and the source, provide a link to the Creative Commons licence, and indicate if changes were made. The images or other third party material in this article are included in the article's Creative Commons licence, unless indicated otherwise in a credit line to the material. If material is not included in the article's Creative Commons licence and your intended use is not permitted by statutory regulation or exceeds the permitted use, you will need to obtain permission directly from the copyright holder. To view a copy of this licence, visit http://creativecommons.org/licenses/by/4.0/.

\section{References}

Papers of particular interest, published recently, have been highlighted as:

- Of importance

- Of major importance

1. Heinzer R, Vat S, Marques-Vidal P, Marti-Soler H, Andries D, Tobback N, et al. Prevalence of sleep-disordered breathing in the general population: the HypnoLaus study. Lancet Respir Med. 2015;3:310-8. https://doi.org/10.1016/S2213-2600(15)00043-0.

2. GBD Chronic Kidney Disease Collaboration. Global, regional, and national burden of chronic kidney disease, 1990-2017: a systematic analysis for the Global Burden of Disease Study 2017. Lancet. 2020;395:709-33. https://doi.org/10.1016/S0140-6736(20)300453.

3. Cowie MR. Sleep apnea: state of the art. Trends Cardiovasc Med. 2017;27:280-9. https://doi.org/10.1016/j.tcm.2016.12.005.

4. Abuyassin B, Sharma K, Ayas N, Laher I. Obstructive sleep apnea and kidney disease: a potential bidirectional relationship? J Clin Sleep Med. 2015;11:915-24. https://doi.org/10.5664/jcsm.4946.

5. Zhang C, Dong H, Chen F, Wang Y, Ma J, Wang G. The HMGB1RAGE/TLR-TNF- $\alpha$ signaling pathway may contribute to kidney injury induced by hypoxia. Exp Ther Med. 2019;17:17-26. https:// doi.org/10.3892/etm.2018.6932 Effects of different hypoxia models in the kidney.

6. O'Neill J, Jasionek G, Drummond SE, Brett O, Lucking EF, Abdulla MA, et al. Renal cortical oxygen tension is decreased following exposure to long-term but not short-term intermittent hypoxia in the rat. Am J Physiol Renal Physiol. 2019;316:F635-45. https://doi.org/10.1152/ajprenal.00254.2018.

7. Abuyassin B, Badran M, Ayas NT, Laher I. Intermittent hypoxia causes histological kidney damage and increases growth factor expression in a mouse model of obstructive sleep apnea. PLoS One. 2018;13:e0192084. https://doi.org/10.1371/journal.pone.0192084.

8. Lu W, Kang J, Hu K, Tang S, Zhou X, Yu S, et al. Angiotensin-(17) relieved renal injury induced by chronic intermittent hypoxia in rats by reducing inflammation, oxidative stress and fibrosis. Braz $\mathrm{J}$ Med Biol Res. 2017;50:e5594. https://doi.org/10.1590/1414$431 X 20165594$

9. Wu X, Gu W, Lu H, Liu C, Yu B, Xu H, et al. Soluble receptor for advanced glycation end product ameliorates chronic intermittent hypoxia induced renal injury, inflammation, and apoptosis via P38/JNK signaling pathways. Oxidative Med Cell Longev. 2016;2016:1015390.

10. Zhang Y, Su X, Zou F, Xu T, Pan P, Hu C. Toll-like receptor-4 deficiency alleviates chronic intermittent hypoxia-induced renal injury, inflammation, and fibrosis. Sleep Breath. 2019;23:503-13. https://doi.org/10.1007/s11325-018-1704-9.

11. Abuyassin B, Badran M, Ayas NT, Laher I. The antioxidant $\alpha$ lipoic acid attenuates intermittent hypoxia-related renal injury in a mouse model of sleep apnea. Sleep. 2019;42(6). https://doi.org/10. 1093/sleep/zsz066 Evidence on the role of oxidative stress in IHinduced kidney damage.

12. Wu X, Chang SC, Jin J, Gu W, Li S. NLRP3 inflammasome mediates chronic intermittent hypoxia-induced renal injury implication of the microRNA-155/FOXO3a signaling pathway. J Cell Physiol. 2018;233:9404-15. https://doi.org/10.1002/jcp.26784. 
13. Campen MJ, Shimoda LA, O'Donnell CP. Acute and chronic cardiovascular effects of intermittent hypoxia in $\mathrm{C} 57 \mathrm{BL} / 6 \mathrm{~J}$ mice. $\mathrm{J}$ Appl Physiol. 2005;99:2028-35.

14.• Morales-Loredo H, Jones D, Barrera A, Mendiola PJ, Garcia J, Pace $\mathrm{C}$, et al. A dual blocker of endothelin $\mathrm{A} / \mathrm{B}$ receptors mitigates hypertension but not renal dysfunction in a rat model of chronic kidney disease and sleep apnea. Am J Physiol Renal Physiol. 2019;316(5):F1041-52. https://doi.org/10.1152/ajprenal.00018. 2019 Complex animal model of kidney injury followed by chronic IH, providing insight into the role of OSA in patients with CKD.

15. Zhang XB, Cai JH, Yang YY, Zeng YM, Zeng HQ, Wang M, et al. Telmisartan attenuates kidney apoptosis and autophagy-related protein expression levels in an intermittent hypoxia mouse model. Sleep Breath. 2019;23:341-8. https://doi.org/10.1007/s11325018-1720-9.

16. $\mathrm{Wu}$ J, Chu Y, Jiang Z, Yu Q. Losartan protects against intermittent hypoxia-induced peritubular capillary loss by modulating the renal renin angiotensin system and angiogenesis factors. Acta Biochim Biophys Sin Shanghai. 2020;52:38-48. https://doi.org/10.1093/ abbs/gmz136.

17. Ogna A, Forni Ogna V, Haba Rubio J, Tobback N, Andries D, Preisig M, et al. Sleep characteristics in early stages of chronic kidney disease in the HypnoLaus cohort. Sleep. 2016;39:945-53. https://doi.org/10.5665/sleep.5660.

18. Adams RJ, Appleton SL, Vakulin A, Hanly PJ, McDonald SP, Martin SA, et al. Association of kidney disease with obstructive sleep apnea in a population study of men. Sleep. 2017;40(1). https://doi.org/10.1093/sleep/zsw015 Cross-sectional study showing that $\mathrm{AHI}$ predicts $\mathrm{CKD}$ in the general population.

19. Canales MT, Hagen EW, Barnet JH, Peppard PE, Derose SF. Sleep apnea and kidney function trajectory: results from a 20-year longitudinal study of healthy middle-aged adults. Sleep. 2018;41:41(1). https://doi.org/10.1093/sleep/zsx181.

20.• Ahmed SB, Ronksley PE, Hemmelgarn BR, Tsai WH, Manns BJ, Tonelli M, et al. Nocturnal hypoxia and loss of kidney function. PLoS One. 2011;6:e19029. https://doi.org/10.1371/journal.pone. 0019029 Longitudinal study demonstrating the role of severe nocturnal hypoxia as a determinant of accelerated GFR decline.

21. Marrone O, Battaglia S, Steiropoulos P, Basoglu O, Kvamme J, Ryan S, et al. Chronic kidney disease in European patients with obstructive sleep apnea: the ESADA cohort study. J Sleep Res. 2016;25:739-45. https://doi.org/10.1111/jsr.12426 Large crosssectional study showing that lowest nocturnal $\mathrm{SaO}_{2}$ predicts CKD in patients with suspected sleep apnea.

22. Molnar MZ, Mucsi I, Novak M, Szabo Z, Freire A, Huch KM, et al. Association of incident obstructive sleep apnoea with outcomes in a large cohort of US veterans. Thorax. 2015;70:888-95. https://doi. org/10.1136/thoraxjn1-2015-206970 Largest study with longitudinal data showing that OSA affects kidney function.

23. Lee YC, Hung SY, Wang HK, Lin CW, Wang HH, Chen SW, et al. Sleep apnea and the risk of chronic kidney disease: a nationwide population-based cohort study. Sleep. 2015;38:213-21. https://doi. org $/ 10.5665 /$ sleep. 4400 .

24. Chu H, Shih CJ, Ou SM, Chou KT, Lo YH, Chen YT. Association of sleep apnoea with chronic kidney disease in a large cohort from Taiwan. Respirology. 2016;21:754-60. https://doi.org/10.1111/ resp.12739.

25. Lin YS, Liu PH, Lin SW, Chuang LP, Ho WJ, Chou YT, et al. Simple obstructive sleep apnea patients without hypertension or diabetes accelerate kidney dysfunction: a population follow-up cohort study from Taiwan. Sleep Breath. 2017;21:85-91. https://doi. org/10.1007/s11325-016-1376-2.

26. Choi HS, Kim HY, Han KD, Jung JH, Kim CS, Bae EH, et al. Obstructive sleep apnea as a risk factor for incident end stage renal disease: a nationwide population-based cohort study from Korea. Clin Exp Nephrol. 2019;23:1391-7. https://doi.org/10.1007/ s10157-019-01779-6 Largest longitudinal retrospective study showing increased incidence of ESRD in OSA.

27. Nicholl DDM, Ahmed SB, Loewen AHS, Hemmelgarn BR, Sola DY, Beecroft JM, et al. Declining kidney function increases the prevalence of sleep apnea and nocturnal hypoxia. Chest. 2012;141:1422-30. https://doi.org/10.1378/chest.11-1809.

28. Tada T, Kusano KF, Ogawa A, Iwasaki J, Sakuragi S, Kusano I, et al. The predictors of central and obstructive sleep apnoea in haemodialysis patients. Nephrol Dial Transplant. 2007;22:1190-7.

29. Forni Ogna V, Ogna A, Pruijm M, Bassi I, Zuercher E, Halabi G, et al. Prevalence and diagnostic approach to sleep apnea in hemodialysis patients: a population study. Biomed Res Int. 2015;2015: 103686-9. https://doi.org/10.1155/2015/103686.

30. Chu G, Suthers B, Moore L, Paech G, Hensley M, McDonald V, et al. Risk factors of sleep-disordered breathing in haemodialysis patients. PLoS One. 2019;14:e0220932. https://doi.org/10.1371/ journal.pone.0220932.

31. Beecroft JM, Pierratos A, Hanly PJ. Clinical presentation of obstructive sleep apnea in patients with end-stage renal disease. J Clin Sleep Med. 2009;5:115-21.

32. Roumelioti ME, Buysse DJ, Sanders MH, Strollo P, Newman AB, Unruh ML. Sleep-disordered breathing and excessive daytime sleepiness in chronic kidney disease and hemodialysis. Clin J Am Soc Nephrol. 2011;6:986-94. https://doi.org/10.2215/CJN. 05720710

33. Nicholl DDM, Ahmed SB, Loewen AHS, Hemmelgarn BR, Sola DY, Beecroft JM, et al. Clinical presentation of obstructive sleep apnea in patients with chronic kidney disease. J Clin Sleep Med. 2012;8:381-7. https://doi.org/10.5664/jcsm.2028.

34. Loewen A, Siemens A, Hanly P. Sleep disruption in patients with sleep apnea and end-stage renal disease. J Clin Sleep Med. 2009;5: 324-9.

35. Parker KP, Bliwise DL, Bailey JL, Rye DB. Polysomnographic measures of nocturnal sleep in patients on chronic, intermittent daytime haemodialysis vs those with chronic kidney disease. Nephrol Dial Transplant. 2005;20:1422-8.

36. Elias R, Chan C, Bradley T. Altered sleep structure in patients with end-stage renal disease. Sleep Med. 2016;20:67-71. https://doi.org/ 10.1016/j.sleep.2015.10.022.

37.• Inami T, Lyons OD, Perger E, Yadollahi A, Floras JS, Chan CT, et al. Effect of ultrafiltration on sleep apnea and cardiac function in end-stage renal disease. Am J Nephrol. 2020;51:139-46. https:// doi.org/10.1159/000505445 Overnight worsening of myocardial performance in patients with ESRD, prevented by fluids removal.

38. Kasai T, Yumino D, Redolfi S, Su MC, Ruttanaumpawan P, Mak S, et al. Overnight effects of obstructive sleep apnea and its treatment on stroke volume in patients with heart failure. Can J Cardiol. 2015;31:832-8. https://doi.org/10.1016/j.cjca.2015.01.001.

39. Kerns ES, Kim ED, Meoni LA, Sozio SM, Jaar BG, Estrella MM, et al. Obstructive sleep apnea increases sudden cardiac death in incident hemodialysis patients. Am J Nephrol. 2018;48:147-56. https://doi.org/10.1159/000489963.

40. Jhamb M, Ran X, Abdalla H, Roumelioti ME, Hou S, Davis H, et al. Association of sleep apnea with mortality in patients with advanced kidney disease. Clin J Am Soc Nephrol. 2020;15:18290. https://doi.org/10.2215/CJN.07880719 In patients with severe CKD, OSA is associated with increased mortality associated with nocturnal hypoxemia.

41. Tuohy CV, Montez-Rath ME, Turakhia M, Chang TI, Winkelman JW, Winkelmayer WC. Sleep disordered breathing and cardiovascular risk in older patients initiating dialysis in the United States: a retrospective observational study using Medicare data. BMC Nephrol. 2016;17:16. https://doi.org/10.1186/s12882-016-0229-3. 
42. Lavie P, Lavie L. Unexpected survival advantage in elderly people with moderate sleep apnoea. J Sleep Res. 2009;18:397-403.

43. Gottlieb DJ, Yenokyan G, Newman AB, O'Connor GT, Punjabi NM, Quan SF, et al. Prospective study of obstructive sleep apnea and incident coronary heart disease and heart failure: the Sleep Heart Health Study. Circulation. 2010;122:352-60. https://doi. org/10.1161/CIRCULATIONAHA.109.901801.

44. Jung HH, Lee JH, Baek HJ, Kim SJ, Lee JJ. Nocturnal hypoxemia and periodic limb movement predict mortality in patients on maintenance hemodialysis. Clin J Am Soc Nephrol. 2010;5:1607-13. https://doi.org/10.2215/CJN.08881209.

45. Elias R, Bradley T, Kasai T, Motwani S, Chan C. Rostral overnight fluid shift in end-stage renal disease: relationship with obstructive sleep apnea. Nephrol Dial Transplant. 2012;27:1569-73. https:// doi.org/10.1093/ndt/gfr605.

46. Tang S, Lam B, Lam J, Chan C, Chow C, Ho Y, et al. Impact of nephrotic edema of the lower limbs on obstructive sleep apnea: gathering a unifying concept for the pathogenetic role of nocturnal rostral fluid shift. Nephrol Dial Transplant. 2012;27:2788-94. https://doi.org/10.1093/ndt/gfr759.

47. Lyons OD, Inami T, Perger E, Yadollahi A, Chan CT, Bradley TD. The effect of fluid overload on sleep apnoea severity in haemodialysis patients. Eur Respir J. 2017;49(4). https://doi.org/ 10.1183/13993003.01789-2016.

48. Harmon RR, De Lima JJG, Drager LF, Portilho N, Costa-Hong V, Bortolotto LA, et al. Obstructive sleep apnea is associated with interdialytic weight gain and increased long-term cardiovascular events in hemodialysis patients. Sleep Breath. 2018;22:721-8. https://doi.org/10.1007/s11325-017-1603-5.

49. Lyons OD, Chan CT, Yadollahi A, Bradley TD. Effect of ultrafiltration on sleep apnea and sleep structure in patients with end-stage renal disease. Am J Respir Crit Care Med. 2015;119(11):1287-94. https://doi.org/10.1164/rccm.201412-2288OC In ESRD patients, fluids removal without changes in uremic status immediately improves sleep apnea.

$50 . \bullet$ Hanly PJ, Pierratos A. Improvement of sleep apnea in patients with chronic renal failure who undergo nocturnal hemodyalisis. N Engl J Med. 2001;344:102-7 No differences in apneas between nights immediately preceding and following dialysis, but significant differences in relationship to dialysis regimens that may be associated with different efficacy on uremic perturbations.

51. Ogna A, Forni Ogna V, Mihalache A, Pruijm M, Halabi G, Phan O, et al. Obstructive sleep apnea severity and overnight body fluid shift before and after hemodialysis. Clin J Am Soc Nephrol. 2015;10: 1002-10. https://doi.org/10.2215/CJN.08760914.

52. Tang SC, Lam B, Ku PP, Leung WS, Chu CM, Ho YW, et al. Alleviation of sleep apnea in patients with chronic renal failure by nocturnal cycler-assisted peritoneal dialysis compared with conventional continuous ambulatory peritoneal dialysis. J Am Soc Nephrol. 2006;17:2607-16.

53. Lacson E Jr, Xu J, Suri RS, Nesrallah G, Lindsay R, Garg AX, et al. Survival with three-times weekly in-center nocturnal versus conventional hemodialysis. J Am Soc Nephrol. 2012;23:687-95. https://doi.org/10.1681/ASN.2011070674.

54. Chan CT, Hanly PJ, Gabor J, Picton P, Pierratos A, Floras JS. Impact of nocturnal hemodyalisis on the variability of heart rate and duration of hypoxemia during sleep. Kidney Int. 2004;65:661-5.

55. Beecroft JM, Duffin J, Pierratos A, Chan CT, McFarlane P, Hanly PJ. Decreased chemosensitivity and improvement of sleep apnea by nocturnal hemodialysis. Sleep Med. 2009;10:47-54. https://doi. org/10.1016/j.sleep.2007.

56. El-Baroudy N, El Falaki M, Hagras A, Galal R, Azmy R, El-Sayed $\mathrm{B}$, et al. Sleep disorders in children and adolescents on regular hemodialysis. Eur J Pediatr. 2020 (in press);179:1139-46. https:// doi.org/10.1007/s00431-020-03611-w.
57. Gomes C, Oliveira L, Ferreira R, Simão C. Sleep disturbance in pediatric patients on automated peritoneal dialysis. Sleep Med. 2017;32:87-91. https://doi.org/10.1016/j.sleep.2016.12.010.

58. El-Refaey AM, Elsayed RM, Sarhan A, Bakr A, Hammad A, Elmougy A, et al. Sleep quality assessment using polysomnography in children on regular hemodialysis. Saudi J Kidney Dis Transpl. 2013;24:714-8.

59. Amin R, Sharma N, Al-Mokali K, Sayal P, Al-Saleh S, Narang I, et al. Sleep-disordered breathing in children with chronic kidney disease. Pediatr Nephrol. 2015;30:2135-43. https://doi.org/10. 1007/s00467-015-3155-x.

60. Mahajan S, Gupta K, Sinha S, Malhotra A, Mahajan S. Effect of kidney transplantation on sleep-disordered breathing in patients with end stage renal disease: a polysomnographic study. Sleep Med. 2018;45:140-5. https://doi.org/10.1016/j.sleep.2017.11.1151.

61. Tandukar S, Hou S, Yabes J, Ran X, Fletcher M, Strollo P, et al. Does kidney transplantation affect sleep and fatigue in patients with kidney disease? Transplantation Direct. 2019;5:e461. https://doi. org/10.1097/TXD.0000000000000895.

62.• Forni Ogna V, Ogna A, Haba-Rubio J, Nowak G, Venetz J, Golshayan D, et al. Impact of kidney transplantation on sleep apnea severity: a prospective polysomnographic study. Am J Transplant. 2020 (in press). https://doi.org/10.1111/atj.15771 Changes in SDB after renal transplantation in relationship to changes in body fluids and fat mass.

63. Lubas MM, Ware JC, Szklo-Coxe M. Sleep apnea and kidney transplant outcomes: findings from a 20-year (1997-2017) historical cohort study. Sleep Med. 2019;63:151-8. https://doi.org/10. 1016/j.sleep.2019.05.014.

64. Fornadi K, Ronai K, Turanyi C, Malavade T, Shapiro CM, Novak $\mathrm{M}$, et al. Sleep apnea is not associated with worse outcomes in kidney transplant recipients. Sci Rep. 2014;4:6987. https://doi.org/ 10.1038/srep06987.

65. Tiwari R, Lyu B, Alagusundaramoorthy S, Astor B, Mandelbrot DA, Parajuli S. Association of diagnosed obstructive sleep apnea with kidney transplant outcomes. Clin Transplant. 2019;33(12). https://doi.org/10.1111/ctr.13747 Data suggest no detrimental effects of OSA in renal transplanted patients.

66. Szentkiralyi A, Czira ME, Molnar MZ, Kovesdy CP, Remport A, Szeifert L, et al. High risk of obstructive sleep apnea is a risk factor of death censored graft loss in kidney transplant recipients: an observational cohort study. Sleep Med. 2011;12:267-73. https://doi. org/10.1016/j.sleep.2010.08.012.

67. Lendvai Z, Pásti K, Szeifert L, Molnár LD, Rusai K, Balassa K, et al. Cardiometabolic correlates of sleep-disordered breathing in renal transplant children. Pediatr Transplant. 2019;23(6):e13529. https://doi.org/10.1111/petr.13529.

68. Patil S, Ayappa I, Caples S, Kimoff R, Patel S, Harrod C. Treatment of adult obstructive sleep apnea with positive airway pressure: an American Academy of Sleep Medicine systematic review, metaanalysis, and GRADE assessment. J Clin Sleep Med. 2019;15: 301-34. https://doi.org/10.5664/jcsm.7638.

69. Guo J, Sun Y, Xue LJ, Huang ZY, Wang YS, Zhang L, et al. Effect of CPAP therapy on cardiovascular events and mortality in patients with obstructive sleep apnea: a meta-analysis. Sleep Breath. 2016;20:965-74. https://doi.org/10.1007/s11325-016-1319-y.

70. Nicholl DD, Hanly PJ, Poulin MJ, Handley GB, Hemmelgarn BR, Sola DT, et al. Evaluation of CPAP therapy on renin-angiotensin system activity in obstructive sleep apnea. Am J Respir Crit Care Med. 2014;190:572-80. https://doi.org/10.1164/rccm.201403$0526 \mathrm{OC}$.

71. Chuang LP, Lin WS, Lee LA, Chang CH, Huang HY, Hu HC, et al. Elevated serum markers of acute kidney injury in patients with obstructive sleep apnea. J Clin Sleep Med. 2019;15:207-13. https://doi.org/10.5664/jcsm.7618.

72. Daskalopoulou EG, Liavvas C, Nakas CT, Vlachogiannis EG, Bouros D, Dombros NV. Obstructive sleep apnoea syndrome 
promotes reversal albuminuria during sleep. Sleep Breath. 2011;15: 589-97. https://doi.org/10.1007/s11325-010-0408-6.

73. Matsumoto T, Murase K, Tachikawa R, Minami T, Hamada S, Tanizawa K, et al. Microalbuminuria in patients with obstructive sleep apnea-chronic obstructive pulmonary disease overlap syndrome. Ann Am Thorac Soc. 2016;13:917-25. https://doi.org/10. 1513/AnnalsATS.201510-655OC.

74. Chen NH, Chou YT, Lee PH, Lin SW, Chuang LP, Lin YS, et al. Reversibility of albuminuria and continuous positive airway pressure compliance in patients of obstructive sleep apnea syndrome. Medicine (Baltimore). 2016;95(26):e4045. https://doi.org/10.1097/ MD.0000000000004045.

75. Kinebuchi S, Kazama J, Satoh M, Sakai K, Nakayama H, Yoshizawa $\mathrm{H}$, et al. The short-term use of continuous positive airway pressure ameliorates glomerular hyperfiltration in patients with obstructive sleep apnea syndrome. Clin Sci (Lond). 2004;107:317-22.

76. Puckrin R, Iqbal S, Zidulka A, Vasilevsky M, Barre P. Renoprotective effects of continuous positive airway pressure in chronic kidney disease patients with sleep apnea. Int Urol Nephrol. 2015;47:1839-45. https://doi.org/10.1007/s11255-015-1113-y.
77. Koga S, Ikeda S, Yasunaga T, Nakata T, Maemura K. Effects of nasal continuous positive airway pressure on the glomerular filtration rate in patients with obstructive sleep apnea syndrome. Intern Med. 2013;52:345-9.

78. Marrone O, Cibella F, Pépin JL, Grote L, Verbraecken J, Saaresranta T, et al. Fixed but not autoadjusting positive airway pressure attenuates the time-dependent decline in glomerular filtration rate in patients with obstructive sleep apnea. Chest. 2018;154: 326-34. https://doi.org/10.1016/j.chest.2018.04.020 Large cohort study showing arrest of decline in eGFR in OSA patients treated with fixed, but not with auto-adjusting, CPAP.

79. Loffler KA, Heeley E, Freed R, Anderson CS, Brockway B, Corbett A, et al. Effect of obstructive sleep apnea treatment on renal function in patients with cardiovascular disease. Am J Respir Crit Care Med. 2017;196(11):1456-62. https://doi.org/10.1164/rccm. 201703-0603OC RCT showing no significant effect of OSA treatment by CPAP on eGFR evolution.

Publisher's Note Springer Nature remains neutral with regard to jurisdictional claims in published maps and institutional affiliations. 